Correction

\title{
Correction: Wang, Y.; et al. Magnesium Alloy Matching Layer for High-Performance Transducer Applications. Sensors 2018, 18, 4424
}

\author{
Yulei Wang ${ }^{1} \mathbb{C}$, Jingya Tao ${ }^{1}$, Feifei Guo ${ }^{1, * \mathbb{C}}$, Shiyang $\mathrm{Li}^{2}$, Xingyi Huang ${ }^{3}$, Jie Dong ${ }^{1, *}$ and \\ Wenwu Cao ${ }^{4}$ \\ 1 National Engineering Research Center of Light Alloy Net Forming, School of Materials Science and \\ Engineering, Shanghai Jiao Tong University, Shanghai 200240, China \\ 2 Department of Instrument Science and Engineering, Shanghai Jiao Tong University, Shanghai 200240, China \\ 3 Shanghai Key Lab of Electrical Insulation and Thermal Aging, Shanghai Jiao Tong University, \\ Shanghai 200240, China \\ 4 Department of Mathematics and Materials Research Institute, The Pennsylvania State University, \\ University Park, PA 16802, USA \\ * Correspondence: guofeifei19850106@163.com (F.G.); jiedong@sjtu.edu.cn (J.D.)
}

Received: 27 June 2019; Accepted: 12 August 2019; Published: 9 September 2019

The authors wish to make the following corrections to this paper [1]:

In the Results and Discussion section of the paper [1], Figures 7 and 8 from another set of simulations using different parameters were mistakenly used, so the correct ones are given below:

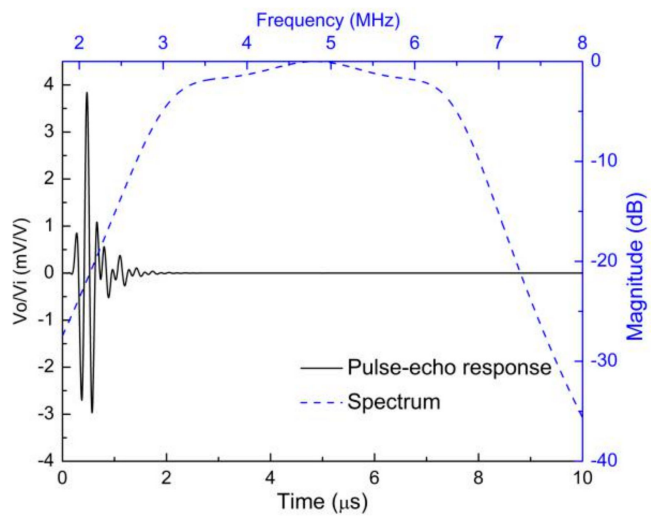

Figure 7. The modeled pulse-echo response and the FFT spectrum of the $5 \mathrm{MHz}$ transducer.

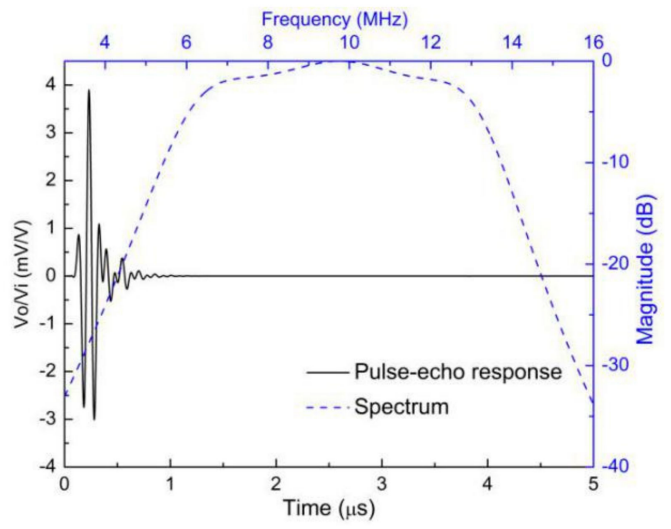

Figure 8. The modeled pulse-echo response and the FFT spectrum of the $10 \mathrm{MHz}$ transducer. 
The designed $5 \mathrm{MHz}$ transducer showed a center frequency of $4.73 \mathrm{MHz}$ after putting the backing and matching layers with a $-6 \mathrm{~dB}$ bandwidth of $77.38 \%$ (corresponding to the lower and upper $-6 \mathrm{~dB}$ frequencies of $2.90 \mathrm{MHz}$ and $6.56 \mathrm{MHz}$ ). The center frequency and $-6 \mathrm{~dB}$ bandwidth for the designed $10 \mathrm{MHz}$ transducer were $9.61 \mathrm{MHz}$ and $77 \%$, respectively (corresponding to the lower and upper $-6 \mathrm{~dB}$ frequencies of $5.91 \mathrm{MHz}$ and $13.31 \mathrm{MHz}$ ). These simulation results agreed well with the experimental results.

In addition, the anti-resonance frequency for the fabricated $5 \mathrm{MHz}$ transducer listed in Table 3 of the paper [1] should be $4.87 \mathrm{MHz}$, instead of $6.0 \mathrm{MHz}$.

\section{References}

1. Wang, Y.; Tao, J.; Guo, F.; Li, S.; Huang, X.; Dong, J.; Cao, W. Magnesium Alloy Matching Layer for High-Performance Transducer Applications. Sensors 2018, 18, 4424. [CrossRef] [PubMed]

(C) 2019 by the authors. Licensee MDPI, Basel, Switzerland. This article is an open access article distributed under the terms and conditions of the Creative Commons Attribution (CC BY) license (http://creativecommons.org/licenses/by/4.0/). 